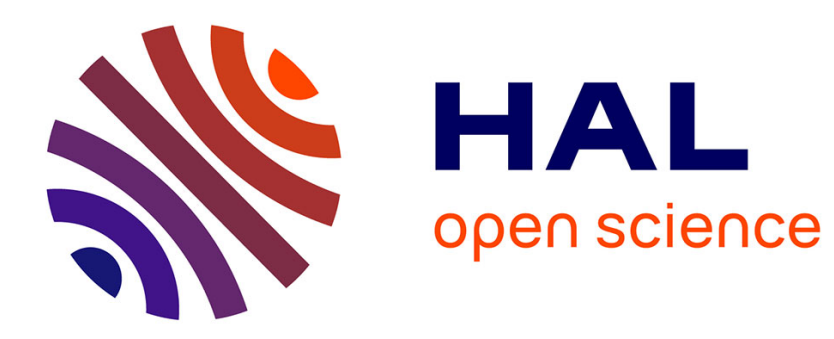

\title{
A laboratory reflEXAFS spectrometer
}

Louis Bosio, Robert Cortès, Guy Folcher

\section{To cite this version:}

Louis Bosio, Robert Cortès, Guy Folcher. A laboratory reflEXAFS spectrometer. Journal de Physique Colloques, 1986, 47 (C8), pp.C8-113-C8-116. 10.1051/jphyscol:1986820 . jpa-00226107

\section{HAL Id: jpa-00226107 https://hal.science/jpa-00226107}

Submitted on 1 Jan 1986

HAL is a multi-disciplinary open access archive for the deposit and dissemination of scientific research documents, whether they are published or not. The documents may come from teaching and research institutions in France or abroad, or from public or private research centers.
L'archive ouverte pluridisciplinaire HAL, est destinée au dépôt et à la diffusion de documents scientifiques de niveau recherche, publiés ou non, émanant des établissements d'enseignement et de recherche français ou étrangers, des laboratoires publics ou privés. 


\section{A LABORATORY REFIEXAFS SPECTROMETER}

L. BOSIO, R. CORTES and G. FOLCHER

Laboratoire CNRS. "Physique des Liquides et Electrochimie", ESPCI, 10, Rue Vauquelin, F-75231 Paris Cedex 05, France

Rés umé :

Nous présentons un spectromètre simple, spécialement construit pour les mesures de ReflexAFS. Il utilise un tube de rayons-X conventionnel associé à un mirolr parabolique. Un monochromateur à deux cristaux (LiF) permet d'obtenir une résolution de $8,5 \mathrm{eV}$ à $8 \mathrm{keV}$. Le faisceau incident est monitoré par un compteur proportionnel et le falsceau réfléchi est mesuré par un compteur à scintillation (NaI) qui permet d'éliminer les harmoniques par discrimination d'énergie. Le spectromètre est utilisable de 7 à 18 keV. Les spectres relatifs à la surface d'un échantilion de nickel avant et après oxydation thermique sont présentés.

Abstract:

A simple spectrometer using a conventional $X-r a y$ generator has been constructed for RefleXAFs measurements at glancing angle. The $X-r$ ay source is a sealed $X-r a y$ tube with a parabolic mirror. A monochromator with two flat lif crystals is used. The energy resolution amounts to 8.5 eV at $8 \mathrm{keV}$. A proportional counter monitors the incident $x$-ray intensity and a NaI scintiliation detector measures the intensity of the reflected beam. This system is free from fluctuations of the incident $X-r a y$ intensity and harmonics can be rejected with the energy discrimination. The range of energy is 7 to $18 \mathrm{keV}$. The ReflEXAFS spectra related to the surface of a nickel sample and a thermaliy oxided nickel sample are presented.

\section{INTRODUCTION.}

The use of a synchrotron radiation source ls very attractive to perform EXAFS measurements because of its unique properties of high flux, small beam divergence, structureless spectrum, and polarization. However the difficulty of accessing such facilities has generated a considerable interest in laboratory systems (1), which can be designed for the user oriented conditions and problems. Several such laboratory facilities have been described (2). However, complicated alignement and control procedures or expensive rotating anode $x$-ray sources are required. In most cases, they are not suitable for ReflExAFS experiments. 
We report here a relatively simple device we use to test the suitability of samples for further synchrotron experiments, since the RefiEXAFs experiments require samples of good quality and special experimental conditions.

\section{GENERAL TECHNIQUE :}

When an X-ray beam impinges on a surface with a glancing angle smaller than a critical angle $\theta c$ ( < 10 mrad for the usual compound in the energy range of interest), it is nearly totally reflected and contains the EXAFS and XANES characteristics of the top of the surface (penetration depth about $3 \mathrm{~nm}$ ). To perform this so-called ReflexAFS technique, a very narrow $X$-ray beam ( $<25 \mu m)$ with a low divergence (< 0.1 mrad) is needed, and it is not possible to use classical devices with a bent crystal for enhancing the flux.

\section{MONOCHROMATOR.}

The monochromator consists of two separated LiF (200) flat crystals in the classical (+ -) arrangement shown in figure 1 . Energy scanning is obtained by directiy rotating the whole two-crystals assembly, attached to the mechanical axis of an accurate incremental angle encoder. The angular displacements of the monochromator are thus made with a typical resolution of 0.002 degree. Accurate parallelism between the two crystals can be achieved with a dc motor. The spacing between the two crystals is monitored by a microcomputer in order to avoid a displacement of the beam with the energy.

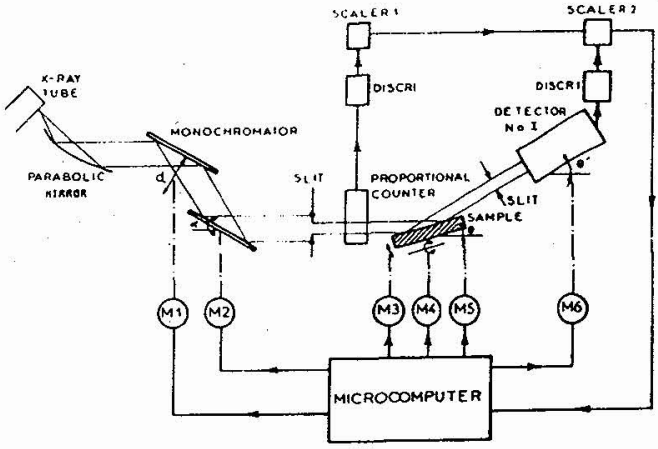

Fig.1. Schematic diagram.

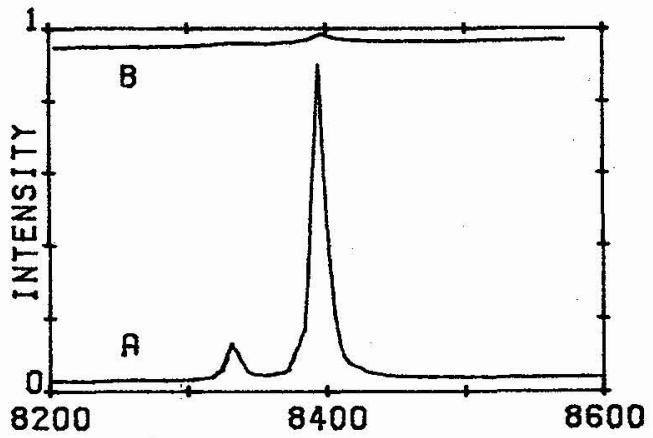

Fig. 2 Counting rate of the scintiliation counter showing the efficiency of the monitor:

A) without monitor

B) with monitor.

\section{X-RAY SOURCE}

The $X-r a y s$ are generated by a conventional sealed $X-r a y$ tube in its line image position. By choosing anode material such as Mo, characteristic lines which may seriously deform the spectra can be, in principle, avoided in the range 7 to $18 \mathrm{keV}$. However the intense characteristic. $L \alpha$ line of tungsten and other spurious lines cannot be avolded, due to the filament evaporation (as shown further below, this difficulty can be overcome by using a monitor set in the incident beam). 
In order to increase the flux without increasing the divergence, a gold-coated parabolic mirror is used. The parabolic form is obtained by bending a glass-plate(160 x $30 \times 3 \mathrm{~mm}^{3}$ ). Thus the flux is about 7 times higher.

MONITOR AND DETECTOR.

$x$-rays coming from the first slit (25 $\mu$ m) pass first through a home-made proportional counter coupled with a fast preamplifier. The counter, equipped with entrance and exit $x-r a y$ tranparent windows (kapton), is filled with P10 gas ( $90 \%$ argon and $10 \%$ methane) at atmospheric pressure so that it absorbs $10-20 \%$ of the $X$-ray beam depending on the energy $r$ ange of interest.

The intensity reflected by the sample is measured by a NaI(T1) scintiliation. detector chosen for its good noise characteristics. It cannot handle count rates much above $10^{5}$ counts $s^{-1}$; but this count rate capability is sufficient for ReflEXAFS measurements where the flux behind the slit never rises above this limit. Harmonics can be rejected with the energy discrimination. Al1 thesignals are counted until the number of photons detected by the first counter reaches the preset number of the dual-scaler. The ratio between the two detectors, without any sample, is shown in figure 2; on account of the lack of detector Iinearity, the W-L $\alpha$ caracteristic line is divided by 300 .

\section{SAMPLE HOLDER.}

In order to make very fine adjustment to the position and the orfentation of the sample, a precise gonfostat was employed. It allows the alignment of the sample parallel to the beam and in the middle of the beam. Then the angular dependence of the reflectivity can be performed ( $f 1 g .3$ ).

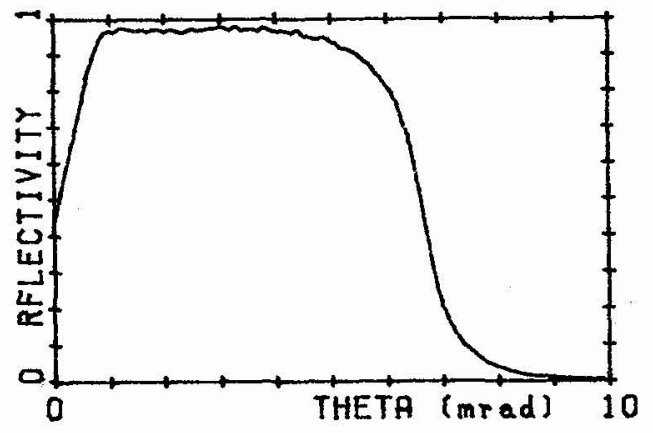

F1g.3. Angular dependence of the refiectivity from Ni at $8200 \mathrm{eV}$

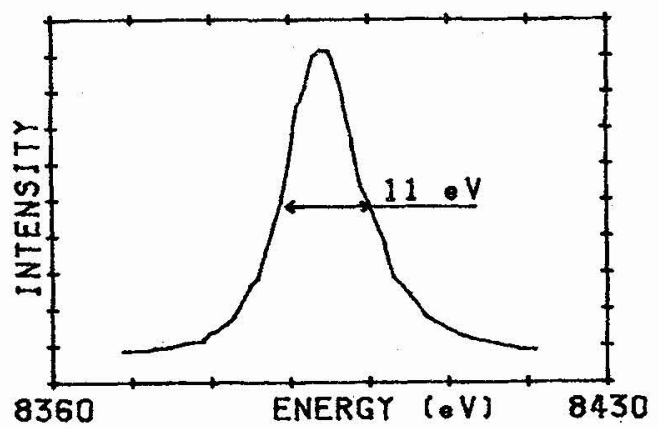

Fig.4. Experimentaly measured $W-L \alpha$ caracteristic ine.

\section{PERFORMANCE AND APPLICATION.}

The experimental resolution was deduced from the measured intensity profile of the characteristic emission line (L $\alpha$ ) of the tungsten impurity (fig. 4). Taking the natural Iine width of about $7.2 \mathrm{eV}$, the actual energy resolution Is evaluated to be $8.5 \mathrm{eV}$. With a silt width set to $25 \mu \mathrm{m}$ the X-ray source operating at $20 \mathrm{kV}$ and $40 \mathrm{~mA} g i v e s$ an $X-r$ ay $f 1$ ux of $5000 \mathrm{cps}$ at $8 \mathrm{keV}$. 
With this system, samples used for studies of protective oxide formation on metal surface (3) can be tested before the final experiments using the synchrotron radiation source. As an example; figure 5 and 6 show the ReflexAFS spectra from a nickel sample before and after oxidation (the duration of the data collection per set was about 6 hours). Indeed the spectra are obtained with relatively poor statistics, but it is sufficient to assess the quality of the samples.
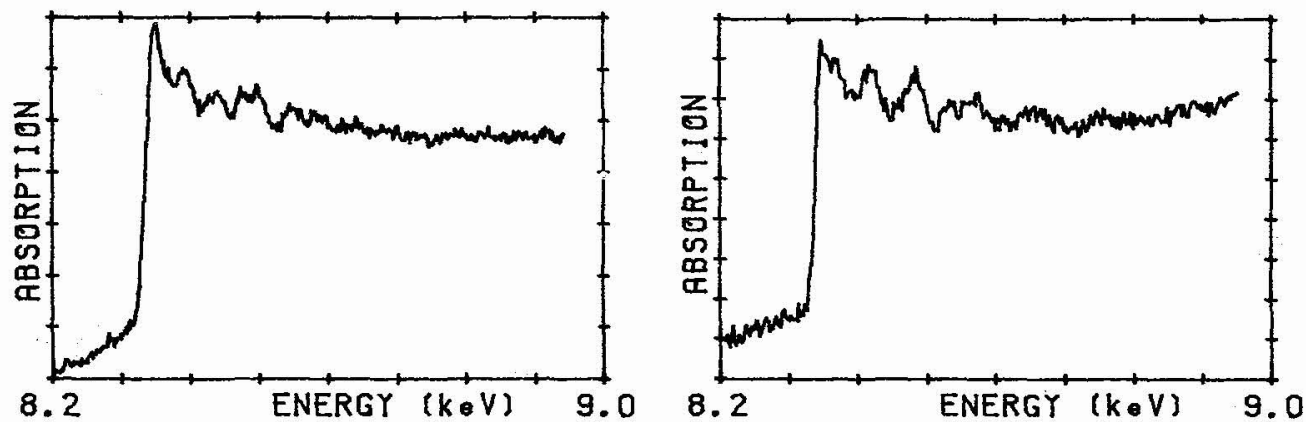

Fig.5. RefIEXAFS spectrum from $(\theta=5.5 \mathrm{mr}$ ad $)$ re oxidation.

Fig.6. Ref1EXAFS spectrum from $(\theta \stackrel{s}{=} 5.5$ af ad $)$ oxidation.

REFERENCES.

(1) E.A. STERN Laboratory EXAFS facilities, AIP Conf. Proc. n. 64 American Institut of Physics, New York, 1980

(2) G.MARTENS and P.RABE. Phys. Stat. Sol. 58, (1980), 415 P.GEOGOPOULOS and G.S.KNAPP. J.App1. Cryst. 14, (1981),3 and ref. therein.

M.SANO, T.MARUO and H. YAMATERA. Bul1. Chem. Soc. Jpn. 57, $(1984), 2757$ and ref. therein.

(3) L.BOSIO, R.CORTES, A.DEFRAIN and M.FROMENT. J. Electroanal. Chem. 180 , (1984) 265 . 